\title{
Water-energy-food nexus: challenges and opportunities
}

\author{
Bellie Sivakumar ${ }^{1}$ (D)
}

Accepted: 27 October 2020 / Published online: 6 November 2020

(C) Springer-Verlag GmbH Germany, part of Springer Nature 2020

Population growth and improved living standards have and continue to increase our basic demands for water, energy, and food. There are serious concerns on the availability of water, energy, and food to meet our current and future demands. For instance, according to some recent estimates, about 768 million people in the world remain without access to an improved source of water (WHO/UNICEF 2013), more than about 1.3 billion people still lack access to electricity (IEA 2012), and about 868 million people are undernourished due to a lack of food or lack of access to food (FAO 2013). Projections for 2050 indicate that global water demand (in terms of water withdrawals) will increase by 55\% (OECD 2012), energy demand from hydropower and other renewable resources will rise by $60 \%$ (WWAP 2009), and food production will need to increase by as much as $60 \%$ to meet the demand (WWAP 2012). Global climate change is anticipated to have serious influences on the water, energy, and food sectors. All these will likely have threatening consequences on our socio-economic development and environmental sustainability.

In view of these, there are urgent and pressing questions about the water, energy, and food sectors, especially in the face of climate change. While these questions have often been independently addressed in the respective fields, such a sectoral approach is clearly inadequate, since there are strong links among the different sectors. For instance: (1) agriculture accounts for about $70 \%$ of global water withdrawal; (2) about $75 \%$ of all industrial water withdrawals are used for energy production; (3) food production and supply chain accounts for about $30 \%$ of global energy consumption; and (4) about $90 \%$ of global power generation is water-intensive. What is needed, therefore, is an integrated approach that can incorporate the complex interactions among the different sectors. In light of this,

Bellie Sivakumar

b.sivakumar@iitb.ac.in

1 Department of Civil Engineering, Indian Institute of Technology Bombay, Powai, Mumbai 400076, India research on the "Water-Energy-Food nexus" (WEF nexus) (and between any two sectors) has been gaining considerable attention in recent years, and the role of climate (change) is also starting to be incorporated.

Despite the efforts and progress in recent years, our understanding of the WEF nexus remains very limited. Many factors contribute to this situation: (1) the systems and the interconnections (both within and between) are inherently complex, and a strong scientific theory for studying such complex dynamically-evolving systems and the associated interconnections is largely absent; (2) there are natural and anthropogenic influences, which are not adequately known; and (3) there are often only limited data. There are also other important factors that are not given the required attention. For instance, there are even questions on the basic definition of the Water-Energy-Food nexus. Literature on these are often scattered and fragmented, which makes it hard to address the Water-EnergyFood nexus in a coherent manner.

This Special Issue is intended to bring together some of the latest, yet scattered, research activities on the WaterEnergy-Food nexus into a single platform, to discuss the major challenges in studying this nexus and the opportunities that exist to address such. The papers together cover a broad range of topics related to research on the WEF nexus, including: (1) concept of the WEF nexus; (2) key natural and anthropogenic factors that influence the WEF nexus; (3) development and application of methods to model the structure, connections, and dynamics of the WEF nexus; (4) role of the WEF nexus in assessing our socio-economic development and environmental sustainability; (5) guidelines for adaptation and mitigation of the negative impacts of the dynamics of the WEF nexus; and (6) formulation of a general and integrated framework to study the WEF nexus in an interdisciplinary and multidisciplinary setting. The contributions also cover WEF nexus studies conducted for many regions around the world, including regions that are highly vulnerable in terms of population growth and socio-economic development, such as Asia, Africa, and South America. 
Acknowledgements First of all, my sincere thanks to George Christakos, the Editor-in-Chief of SERRA, for his encouragement and support for this Special Issue in the first place. I very much appreciate the time and effort by George as well as by Magesh Nagarajan, at the SERRA Editorial Office, throughout the review process. The authors of the contributions deserve my special thanks for their support and participation in this endeavor, despite their numerous commitments and time constraints. The Special Issue has also benefited from the following reviewers (in alphabetical order): Bente Castro Campos, Nadir Ahmed Elagib, Ping Guo, Nick Holden, Tailin Huang, Shokhrukh Jalilov, Shaofeng Jia, Doosun Kang, Chunhui Li, Mo Li, Tianxiao Li, Yu Li, Wenfeng Liu, Beatriz Mayor, Weiwei Mo, Jun Niu, Rudi Pretorius, Haiyun Shi, Janez Susnik, Koichi Unami, Hongrui Wang, Huimin Wang, and Hongbo Zhang. Their timely and constructive reviews have certainly enhanced the quality of the contributions, and my sincere thanks to each and every one of them.

\section{References}

FAO (Food and Agriculture Organization of the United Nations) (2013) The state of food and agriculture 2013: food systems for better nutrition. FAO, Rome
IEA (International Energy Agency) (2012) Water energy outlook 2012. OECD/IEA, Paris

OECD (Organisation for Economic Co-operation and Development) (2012) OECD environmental outlook to 2050: the consequences of inaction. OECD, Paris

WHO/UNICEF (World Health Organization/United Nations Children's Fund) (2013) Progress on sanitation and drinking-water: 2013 update. WHO/UNICEF Joint Monitoring Programme for Water Supply and Sanitation, New York

WWAP (World Water Assessment Programme) (2009) The United Nations world water development report 3: water in a changing world. UNESCO/Earthscan, Paris

WWAP (World Water Assessment Programme) (2012) The United Nations world water development report 4: managing water under uncertainty and risk. UNESCO, Paris

Publisher's Note Springer Nature remains neutral with regard to jurisdictional claims in published maps and institutional affiliations. 